\title{
The Pattern of Appearance Schema in Patients with Dermatological Disorder
}

\author{
Paramita Datta $_{1}$, Amrita Panda $_{2}$, Mallika Banerjee 3
}

\section{ABSTRACT:}

There has been a stigma attached to diseases of the skin for centuries. A healthy normal skin is essential for a person's physical and mental well-being and sense of self-confidence. It has been estimated that approximately one third of the patients presenting with the dermatological disorders have some psychological co-morbidity (Rosenberg, 1960). Literature has shown that patients with vitiligo and acne are mostly affected by their psychosocial wellbeing, whereas psoriasis and atopic dermatitis patients are affected by both physical and psychosocial well-being. Self-evaluative salience reflects the importance of appearance to one's sense of self-worth. A person who is self-evaluative define or measure themselves and their self-worth by their physical appearance and it deem influential in their social and emotional experiences. The present study aimed to evaluate any difference between appearance schema self-evaluative salience among the patients of psoriasis, acne, vitiligo and their controlled counterparts. Total 200 samples, 50 patients (Mean age $=32.8$ years, $\mathrm{SD}=3.97$ years) for each group were chosen following purposive sampling technique from Department of Dermatology, R. G. Kar Medical College, Kolkata, India. The Appearance Schemas Inventory-Revised (ASI-R) was used to measure evaluation of appearance schema of the participants. Results indicate a significantly higher salience of self-evaluative appearance schema in patients with acne, followed by patients with psoriasis, vitiligo and their controlled counterparts. The findings indicate that the control group outperforms their clinical counterparts significantly in self evaluative appearance schema measure. The effect size measure indicates a small impact of dermatological disorder on self-evaluative appearance schema, indicating though prevails the stigma of dermatological disorders in our society; the patients acquire effective coping strategies to boost their self esteem. Their body image is not primarily guided by evaluation of their appearances. To support this view, it is found that though among these three diseases social stigma is associated more with vitiligo, but the patients with acne have a higher self-evaluative appearance schema. The pattern of the effects of dermatological disorder on self evaluative appearance schema is discussed

Keywords: Appearance, Schema, Dermatological Disorder, Psychological Wellbeing, Acne

\footnotetext{
${ }^{1}$ Research Scholar, Department of Psychology, University of Calcutta, 92 Acharya Prafulla Chandra Road, Kolkata

${ }^{2}$ Project Fellow, Centre for the Study of Developmental Disability, Special Assistance Programme (DRS I), University Grants Commission, Department of Psychology, University of Calcutta, 92 Acharya Prafulla Chandra Road, Kolkata.

${ }^{3}$ Professor, Centre for the Study of Developmental Disability, Special Assistance Programme (DRS I), University Grants Commission, Department of Psychology, University of Calcutta, 92 Acharya Prafulla Chandra Road, Kolkata.
}

(C) 2015, P Datta, A Panda, M Banerjee; licensee IJIP. This is an Open Access Research distributed under the terms of the Creative Commons Attribution License (http://creativecommons.org/licenses/by/2.0), which permits unrestricted use, distribution, and reproduction in any Medium, provided the original work is properly cited. 


\section{INTRODUCTION:}

A relationship between dermatological conditions and psychological factors had long been observed (Ahmed, Leon, Butler, \& Reichenberg, 2013; Ongenae, Beelaert, van Geel, \& Naeyaert, 2006). Psychosocial factors have a significant impact upon the overall morbidity associated with skin disorders and therefore constitute an important component of treatment outcome. If psychosocial morbidity untreated then it may also have an adverse impact upon the overall response of skin condition to dermatologic therapies. Appearance of a person is determined by dermatological health to a great extent and plays a major function in social and sexual communication. A healthy normal skin is essential for a person's physical and mental well-being and sense of self-confidence. It has been estimated that approximately one third of the patients presenting with the dermatological disorders have some psychological co-morbidity (Rosenberg, 1960). Psychosocial problems related with skin diseases include problem in interpersonal relationship, shame, feeling of embarrassment, poor self-esteem, lack of self -confidence, depression, even in some extreme cases suicide (Wang, Wang, \& Zhang, 2011; Bashir, Dar, \& Rao, 2010; Lundberg, Johannesson, Silverdahl, Hermansson, \& Lindberg, 2000; Schipper, Cinch, \& Olweny, 1996; Lewis-Jones, \& Finlay, 1995).

Disfiguring appearance is associated with body image concerns. Though we claim to believe "beauty is only skin deep", but people are very likely to respond positively to those who are attractive and negatively to those who are unattractive (Griffin \& Langlois, 2006; Collins \& Zebrowiz, 1995). Appearance plays a important role in person's social and emotional functioning. Appearance specially facial appearance is important aspect of one's perception of body-image. According to the psychosocial research physically attractive strangers attribute more positive qualities such as friendliness, higher social skill levels to each other than physically unattractive strangers. Several experimental and observational studies have subsequently shown that people often react negatively toward someone with a visible skin condition (Grandfield, Thompson \& Turpin, 2005). A person's sense of their own physical appearance, usually in relation to others or in relation to some cultural "ideal" can shape their body image. Persons who are appearance schematic have more investment in how they look and will be more attuned to and more likely reactive to appearance related stimuli (Cash \& Labargl, 1996; Cash, Phillips, Santos \& Hrabosky, 2004). These cognitive processes engender dysphoric reaction, such as self-conscious anxiety, shame or dejection.

Body image is a dynamic concept with ongoing changes that must be integrated as the individual matures. A person's body image is a product of their personal experiences, personality and various social and cultural forces. A person's perception of their appearance can be different from how others actually perceive them. Appearance -related critical comments negatively influence one's body-image. Body-image distress is mostly 
associated with the third type of psychocuteneous disease that is disfiguring skin condition in which psychological issues are secondary.

According to literature psoriasis is associated with problems in body image (Kotrulja, Tadinac, Joki-Begi \& Gregurek 2010). Patients with visible psoriasis are affected psychosocially because of their altered body image (Khoury, Danielsen \& Skiveren, 2014). Similarly, acne vulgaris is also associated with significant psychological distress, regardless of their acne severity patient with this disease have substantial distress and preoccupation related to their facial appearance (Bowe, Leyden, Crerand, Sarwer \& Margolis, 2007).

Skin diseases like acne, psoriasis, and vitiligo produce cosmetic disfigurement and are widely prevalent in every part of world. Review of literature indicates that degree of social anxiety, social avoidance, social withdrawal, general anxiety, depression and negative automatic thoughts, were significantly higher in acne patients resulting in a lowered self-esteem in acne patients (Yolac, Demirci, Erdi \& Devrimci, 2008). Severe acne conglobate has risk of suicide, especially in men (Harth, Hillert, Hermes, Seikowskik, Niemeier, \& Freudenmann, 2008). Acne and other skin diseases have a significant impact on patient's quality of life (Boehncke, Ochsendorf, Paeslack, Kaufmann \& Zollner, 2002). Severe facial blemishes of any cause have a significant impact on women's quality of life (Balkrishnan, McMichael, Hu, Camacho, Shew \& Bouloc, et.al. 2006).

Acne is associated with significant mental health problems due to a heightened sense of shame relating to appearance (Kellett \& Gilbert, 2001). Study also indicate that the most significant emotional impact of acne on medical students was embarrassment (Ali, Mehtab, Sheikh, Ali, Abdel \& Mansoor, et.al. 2010). Magin, Heading, Adams, \& Pond (2010) have shown that acne had adverse effect on self-perceived sexual attractiveness and selfconfidence resulting in marked behavioral avoidance of intimate situation and continuing effects on sexual well being in long established sexual relationship. Acne patients suffer particularly under social limitations and reduced quality of life (Niemeier, Kupfer \& Gieles, 2006).

Patients with psoriasis have an increased risk of depression, anxiety, and suicidality (Kurd, Troxel, Crits-Christop \& Gelfand, 2010). Psoriasis produces significant psychosocial disability. Psychiatric morbidity is significantly correlated with psoriasis (Mattoo, Handa, Kaur, Gupta, \& Malhotra, 2005). Psoriasis affects the quality of life (Rakhesh, D’Souza \& Sahai, 2008). Psoriasis vulgaris interacts with anxiety and depression (Nasreen, Ahmed, Effendi, 2008). Finzi, Colombo \& Caputo (2007) observed psychological distress and planning and active coping were the coping strategies most frequently employed by psoriasis patients.

Experiences of stigmatization were often perceived to be associated with cultural values related to appearance, status, and myths linked to the cause of vitiligo (Thompson, Clarke, Newell \& Gawkrodger, 2010). psychological disturbances as a consequence of vitiligo are common (Osman, Elkordufani \& Abdhullah, 2009). the quality of life is closely elated to the patients' apprehensions about their disease, psychosocial adjustment, and psychiatric morbidity, rather than the clinical severity of the condition itself (Choi, Kim, Whang, Lee, 
Hann \& Shin, 2010). Generalized vitiligo is a serious skin disorder with an adverse impact on the emotional state (Linthorst Homan, Spuls, De Korte, Bose, Sprangers \& Van de veen, 2009).

Evaluation of appearance schema works in the context of a cultural frame a person lives in. A detailed survey of the available research findings point out that though acne, psoriasis, and vitiligo as well as the other psychosocial variables ( quality of life, self-esteem, bodyimage appearance schema, body-image coping strategies and body image cognitive distortion) have been addressed in numerous research findings, there is still the need to study pattern of the way these patients evaluate their appearance schema and its effect on the psychosocial aspect of a person. In absence of sufficient reported study in Indian context this research is an attempt to unveil the persona of a patient with skin disorder and evaluate the possible difference, if any, among three types of skin disorders.

\section{METHOD}

\section{Participants}

The participants were selected using purposive sampling technique. Total number of participants were 200 (Mean age $=32.8$ years, $\mathrm{SD}=3.97$ years). Participants were divided in three experimental groups with three type of skin disorder, i.e., psoriasis, acne, vitiligo and one group of comparable controlled counterparts. Each group consisted of 50 participants each. The participants were chosen from Department of Dermatology, R.G. Kar Medical College and Hospital, Kolkata, India.

\section{Selection Criteria}

\section{$\underline{\text { Inclusion criteria }}$}

1. Age between 18 to 50 years.

2. The prevalence of these three diseases is found equally in both the sex. So both males and females were selected as participants for the study.

3. Disease on exposed areas of the body, namely face, neck, upper and lower limbs were only included.

\section{$\underline{\text { Exclusion criteria }}$}

1. Any psychiatric illness

2. Any physical disability 


\section{Tools Used}

Information Schedule: The information schedule was prepared by the present investigator to collect a short case history of each of the participants as per the requirements of the present study.

The Appearance Schemas Inventory (ASI-R): To measure belief about appearance the Appearance Schemas Inventory-Revised (ASI-R) was used. ASI-R is an empirically validated, extensive revision of Cash and Labarge's (1996) original assessment of individual's psychological investment in their physical appearance.

\section{Procedure}

First, Bengali translation of Appearance Schema Inventory (ASI-R) were done following the translation protocol of EORTC quality of life group translation procedure by Cull, Sprangers, Bjordal, Aaronson, West \& Bottomley (2002) and a Bengali working norm of ASI-R was established. Then the screening and diagnosis of dermatological disorder were made by consultant dermatologists of respective hospitals. Only patients of psoriasis, acne, vitiligo were included in the study. Patients with disorders on exposed area of body were only included. All the participants were explained about the nature of the present study. They were assured about confidentiality of their identity and responses. Detailed case history was taken for screening out any other psychiatric illness and other physical disability. Then the Bengali translated Appearance Schemas Inventory - Revised (ASI-R) was administered to the three experimental groups (150 patients). The control group consisted of 50 subjects, both male and female without clinically significant skin disease and any other reported physical disability and psychiatric illness. The control group was matched with the experimental groups according to their socioeconomic status, gender, age. The data were tabulated following the scoring key of each questionnaire and for each individual separately. The entire data were analyzed using SPSS 21. Univariate ANOVA and Tukey post hoc test were used to find the difference among the groups on appearance schema scores. 


\section{RESULT}

Table 1: Showing the descriptive and inferential statistics among three experimental groups and control group

\begin{tabular}{|c|c|c|c|c|c|c|c|c|}
\hline & $\begin{array}{c}\text { Psoriasis } \\
(\mathrm{N}=50)\end{array}$ & Acne & Vitiligo & $\begin{array}{c}\text { Control } \\
\text { Group }\end{array}$ & $\mathrm{F}$ & $\mathrm{df}$ & P- Value & $\begin{array}{c}\text { Effect } \\
\text { Size }\end{array}$ \\
& $(\mathrm{N}=50)$ & $(\mathrm{N}=50)$ & & & & \\
\hline Mean & 2.79 & 3.19 & 2.75 & 2.66 & 4.52 & 3 & .01 & .065 \\
\hline SD & 0.86 & 0.79 & 0.70 & 0.72 & & & & \\
\hline
\end{tabular}

Table 2: Showing the Post-hoc analysis among the three experimental groups

\begin{tabular}{|l|l|c|c|}
\hline \multirow{5}{*}{ Group } & Difference & Mean Difference & Sig. \\
\hline \multirow{4}{*}{ Psoriasis } & Acne & -.3994 & .053 \\
\cline { 2 - 4 } & Vitiligo & .0368 & .995 \\
\cline { 2 - 4 } & Control & .1284 & .842 \\
\hline \multirow{5}{*}{ Vitiligo } & Psoriasis & .3994 & .053 \\
\cline { 2 - 4 } & Vitiligo & $.4362^{*}$ & .028 \\
\cline { 2 - 4 } & Control & $.5278^{*}$ & .005 \\
\hline \multirow{5}{*}{ Control } & Psoriasis & -.0368 & .995 \\
\cline { 2 - 4 } & Acne & $-.4362^{*}$ & .028 \\
\cline { 2 - 4 } & Control & .0916 & .935 \\
\hline & Psoriasis & -.1284 & .842 \\
\cline { 2 - 4 } & Acne & $-.5278^{*}$ & .005 \\
\cline { 2 - 4 } & Vitiligo & -.0916 & .935 \\
\hline
\end{tabular}




\section{DISCUSSION}

From fairy tales to moral stories, from infant rhymes to adult novels, society teaches us to be over concerned by appearance, be it from Helen of Troy or Cinderella and her ugly step sisters or Kiranmala and her terrifying wicked step mother and like, literature in all transcripts of the world shows that. One of the major characteristics of human being which differentiate them from other animals is stigmatization by appearance.

For a human being face is the most acceptable communicator and seat of recognition of appearance. Any disfigurement in this face may result in a challenging adjustment, coping and as a whole challenging mental health. Acceptance of these challenges depends on various psychological issues alongwith medical and social issues.

Person's own perception and investment toward facial appearance are positively related with his/her global self worth and self perceived social acceptance. Research findings showed that dissatisfaction with self appearance was associated with relationship problems and global self esteem (Pope \& Ward, 1977).

The present research work aims to highlight some psychological issues related to appearance, viz., perceived distress as a result of facial disfigurement including recommendation to pay proper medical attention on this issue and psychosocial rehabilitation.

In the field of Psychophysiological research, Psychodermatology is relatively young which demands the interaction between skin and mind. Skin responds to both exogenous and endogenous stimuli. It encodes external pattern of social perception, i.e., perceived negative cues of the society and decoded and transmit internal conditions to the outside world. Though it is obvious that not everyone responds emotionally through skin or not every disfigurement of skin results psychological disturbance to everyone but evidences suggest that skin physiology often intersects with psychological issues. So, the treatment considering this interaction may offer the best result.

Among various skin diseases the present study has focused on acne, psoriasis and vitiligo considering the ladder of social stigma as attached with these three types of diseases where vitiligo is most stigmatized followed by psoriasis and acne. Though acne is relatively less stigmatized and less severe in nature as considered by general population, the hospital outdoors and clinics revealed picture of acne as most frequently complained disease carried out by most negatively affected quality of life and adjustment.

Surprisingly, the result of the present study also shows that in comparison to psoriasis and vitiligo, patients with acne invest their energy more towards their appearance in comparison to that of other two counterparts which means that schematic investment in own appearance is more in person with acne. It also suggest that the acne group tends to be more selfevaluative than psoriasis, vitiligo and their control counterpart.. It means that the patient 
with acne measure themselves and their self-worth mostly by their physical appearance which may influence their social and emotional experiences also. According to literature patient with acne have a stronger attentional bias for acne lesions and focus more on the skin lesions than without acne (Lee, Lee, Lee, Park, Chung, Wallraven et. al., 2014). Another study which examined appearance related distress of acne patients suggest that the acne patients above 20 years significantly suffer appearance related distress. According to this study for both men and women acne was significantly associated with bodily selfconsciousness of appearance (Hassan, Grogan, Clark-Carter, Richards, \& Yates, 2009). So, from the present study as well as with some past literature, it can be said that the acne patients give more importance to their appearance, which may lead to mental health problems.

Now, the research question may arise that why acne as a disease demands more appearance investment, a negative psychological component, of the patient in comparison to other two skin diseases in spite of its less severity and stigmatization? As a causal factor the most common psychological component, viz., 'frustration' can be attributed for this negative investment. In the present study duration of illness was around 6 years. Though the severity is less in comparison to other skin diseases and apparently prognosis is good but the frequent attack of the disease put negative effect on their level of expectation for cure. They expect rapid cure, failure of which leads to frustration. Feeling of hopelessness and social distance take place which may cause psychological ailments including depression, suicidal ideation and anxiety. Psychosomatic symptoms, including pain and discomfort, embarrassment and social inhibition, can also occur (Koo, 1995).

So from above discussion it can be inferred that as a disease acne is less severe in comparison to other two disfiguring diseases and prognosis is better but still due to frequent recurrence acne patients suffer more psychological problems in comparison to that of psoriasis and vitiligo. It can be inferred that patients with acne gives more importance to their disfiguring appearance and it may leads to significant psychosocial impact on one's life.

So, from the present study, it can be recommended to both psychologists and dermatologists not to underestimate the impact of acne and to provide appropriate degree of hope for cure to the patient with acne. Also, proper psychoeducation to the patient as well as to the wider community can be recommended. Another important reflection of the present finding is, if such a common diseased condition demands such strong attention driven by the fear of social rejection the task of treatment both for psychologists and physician will be myriad for other severe dermatological diseases. 


\section{REFERENCE}

1. Ahmed, A., Leon, A., Butter, D. C., \& Reichenberg, J. (2013). Quality of life effects of common dermatological diseases. Seminars in cutaneous medicine and surgery, 32(2), $101-9$.

2. Ali, G., Mehtab, K., Sheikh, Z. A., Ali, H. G., Abdel Kader, S., Mansoor, H., Attaf, S., Qamar, S., \& Khwja, S. S. (2010). Beliefs and perceptions, of acne among a sample of students from Sindh Medical college, Karachi. The Journal of Pakistan Medical Association, 60(1), 51-4.

3. Balkrishnan, R., McMichael, A. J., Hu, J. Y., Camacho, F. T., Shew, K. R., Bouloc, A., Rapp, S. R., \& Feldman, S. R. (2006). Correlates of health-related quality of life in women with severe facial blemishes. International Journal of Dermatology, 45(2), 111-5.

4. Bashir, K., Dar, N. R., \& Rao, S. U. (2010). Depression in adult dermatology outpatients. Journal of the college of physicians and surgeons-Pakistan, 20(12), 811-3.

5. Bowe, W. P., Leyden, J. J., Crerand, C. E., Sarwer, D. B., \& Margolis, D. J. (2007). Body dysmorphic disorder symptoms among patients with acne vulgaris. Journal of the American Academy of Dermatology, 57(2), 222-30.

6. Boehncke, W. H., Ochsendorf, F., Paeslack, I., Kaufmann, R., \& Zollner, T. M. (2002). Decorative cosmetics improve the quality of life in patients with disfiguring skin diseases. European Journal of Dermatology, 12(6), 577-80.

7. Cash, T. F., \& Labarge, A. S. (1996). Development of the Appearance Schemas Inventory: A new cognitive body-image assessment. Cognitive Therapy and Research, 1, 37-50.

8. Cash, T. F., Melnyk, S. E., \& Hrabosky, J. I. (2004). The assessment of body-image investment: An extensive revision of the Appearance Schema Inventory. International Journal of Eating Disorders, 35, 305-316.

9. Cash, T. F., Phillips, K. A., Santos, M. T., \& Hrabosky, J. I. (2004). Measuring "negative body image": Validation of the body image disturbance questionnaire in a non-clinical population. Body Image, 1, 363-372.

10. Choi, S., Kim, D. Y., Whang, S.H., Lee, J. H., Hann, S. K., Shin, Y. J. (2010). Quality of life and psychological adaptation of Korean adolescents with vitiligo. Journal of the European Academy of Dermatology and Venereology, 24(5), 524-9.

11. Collins, M. A., \& Zebrowitz, L. A (1995). The contributions of appearance to occupational

12. outcomes in civilian and military settings. Journal of Applied Social Psychology,

13. $25,129-163$.

14. Cull, A., Sprangers, M. A. G., Bjordal, K., Aaronson, N. K., West, K., \& Bottomley, A. (2002). On behalf of the EORTC Quality of Life Group. EORTC Quality of Life Group Translation Procedure (2nd edition). EORTC Quality of Life Group Publication, Brussels.

15. Griffin, A. M., Langlois, J. H.(2006).Stereotype directonality and attractiveness stereotyping: Is beauty good or is ugly bad? Social Cognition, 24(2), 187-206.

16. Grandfield, T. A., Thompson, A. R., Turpin, G. (2005). An attitudinal study of responses to a range of dermatological conditions using the implicit association test. Journal of Health Psychology, 10(6), 821-9.

17. Harth, W., Hillert, A., Hermes, B., Seikowski, K., Niemeir, V., Freudenmann, R. W. (2008). Suicidal behaviour in dermatology. Der Hautarzt, 59(4), 289-96. 
18. Hassan, J., Grogan, S., Clark-Carter, D., Richards, H., \& Yates, V. M. (2009). The individual health burden of acne, appearance-related distress in male and female adolescents and adults with back, chest and facial acne. Journal of health psychology, 14(8), 1105-18.

19. Kortulja, L., Tadinac, M., Joki-Begi, N. A., Gregurek, R. (2010). A multivariate analysis of clinical severity, psychological distress \& psychopathological distress and psychopathological traits in psoriatic patients. Acta Dermato-Venereologica, 90(3), 2516.

20. Koo, J. (1995). The psychosocial impact of acne: patients' perceptions. Journal of American academy of dermatology, 32(5 Pt 3), S26-S30.

21. Kurd, S. K., Troxel, A.B., Crits-Christoph, P., \& Gelfand, J. M. (2010). The risk of depression, anxiety and suicidality in patients with psoriasis a population-based cohort study. Archives of dermatology, 146(8), 891-5.

22. Lee, I. S., Lee, A. R., Lee, H., Park, H. J., Chung, S. Y., Wallraven, C., Bulthhoff, I. \& Chae, Y. (2014). Psychological distress and attentional bias toward acne lesions in patients with acne. Psychology health and medicine, 19(6), 680-6.

23. Lewis-Jones, M. S., \& Finlay, A. Y. (1995). The children's dermatology life quality index: Initial validation and practical use. British Journal of Dermatology, 132: 942-949.

24. Lundberg, L., Johannesson, M., Silverdahl, M., Hemansson, C., \& Lindberg, M. (2000). Health -related quality of life in patients with psoriasis and atopic dermatitis measured with SF-36, DLQI and a subjective measure of disease activity. Acta dermatovenereologica, 80(6), 430-4.

25. Linthorst Homan, M. W., Spuls, P. I., De Korte, J., Bose, J. D., Sprangers, M. A., Van de Veen, J. P. (2009). The burden of vitiligo: patient characteristics associated with quality of life. Journal of the American Academy of Dermatology, 61(3), 411-20.

26. Magin, P., Heading, G. S., Adams, J., \& Pond, D. P. (2010). Sex and the skin: A qualitative study of patients with acne, psoriasis and atopic eczema. Psychology, Health and Medicine, 15, 454-462.

27. Mattoo, S. K., Handa, S., Kaur, I., Gupta, N., \& Malhotra, R. (2005). Psychiatric morbidity in psoriasis: Prevalence and correlates in India. Ger J Psychiatry, 8:17-22.

28. Nasreen, S., Ahmed, I., \& Effendi, S. (2008). Frequency and magnitude of anxiety and depression in patients with psoriasis vulgaris. Journal of the college of physicians and surgeons Pakistan, 18(7), 397-400.

29. Niemeier, I., Kupfer, J., \& Gieles, U. (2006). Acne vulgaris- psychosomatic aspects. Journal Der Deutschen Dermatologischen Gesellschaft, 4(12), 1027-36.

30. Ongenae, K., Beelaert, L., Van Geel, N., \& Naeyaert, J. M. (2006). Psychosocial effects of vitiligo. Journal of the European Academy of Dermatology and Venereology, 20(1), 18.

31. Osman, A. M., Elkordufani, Y., \& Abdullah, M. A. (2009). The psychological impact of vitiligo in adult Sudanese patients. African Journal of psychiatrist, 12(4), 284-6.

32. Pope, A. W., \& Ward, J. (1977). Self-perceived facial appearance and psychosocial adjustment in preadolescents with craniofacial anomalies. The Cleft Palate Craniofacial Journal, 34 (5), $396-408$.

33. Rakhesh, S.V., D'Souza, M., \& Sahai, A. (2008). Quality of life in psoriasis: a study from south India. Indian Journal of dermatology, venereology and leprology, 74(6), 6006. 
34. Rostenberg, A. Jr (1960). The role of psychogenic factors in skin disease. Archives of Dermatology, 81, 81-3.

35. Schipper, H., Clinch, J. J., \& Olweny, C. L. M. (1996). Quality of life studies: definitions and conceptual issues. In: Spilker B., editor. (ed.), Quality of Life and Pharmacoeconomics in Clinical Trials, 2nd edn. Philadelphia, PA: Lippincot-Raven Publishers, pp. 11-23.

36. Thompson, A. R., Clarke, S. A., Newell, R. J., \& Gawkrodger, D. J. (2010). Vitiligo linked to stigmatization in British South Asian women: a qualitative study of the experiences of living with vitiligo.. British Journal of Dermatology, 163(3), 481-6.

37. Yolac Yarpuz, A., Demirci Saadet, E., Erdi Sanli, H., \& Devrimci Ozquven, H. (2008). Social anxiety level in acne vulgaris patients and its relationship to clinical variables. Turkish Journal of Psychiatry, 19(1), 29-37.

38. Wang, K. Y., Wang, K. H., \& Zhang, Z. P. (2011). Health-related quality of life and marital quality of vitiligo patients in China. Journal of European Academy of Dermatology and Venereology, 25(4):429-435. 